Sanusi et al., Afr. J. Infect. Dis. (2015) 9(2): 61 - 66

http://dx.doi.org/10.4314/ajid.v9i2.9

\title{
EPIDEMIOLOGY OF BACTERIA COLONIZATION AND ICU-ACQUIRED INFECTION IN A NIGERIAN
} TERTIARY HOSPITAL

\author{
Arinola A. Sanusi ${ }^{a}$, Babatunde B. Osinaike ${ }^{a}$ Samuel A. Fayemiwo*b Victor U. Nwadike $^{\text {b }}$ \\ Tinuola A. Adigun ${ }^{a}$, Olawale O. Olusanya ${ }^{b}$, Rasheed A. Bakare ${ }^{b}$
}

Akinola O. Akinyemi ${ }^{a}$

\author{
Department of Anaesthesia ${ }^{a}$ and Department of Medical Microbiology and Parasitology ${ }^{\mathrm{b}}$, College of Medicine, \\ University of Ibadan/ University College Hospital, Ibadan, Nigeria. \\ *E-mail: dayteet@yahoo.com
}

\begin{abstract}
Background: Health care associated infection (HCAI) or Hospital acquired infection is associated with significant morbidity, mortality and cost. The incidence is about $6 \%$ and disproportionately higher in critically ill patients who may have been immune-compromised with many invasive procedures already performed. Prevention of HCAI and appropriate management of patients in the intensive care unit (ICU) requires knowledge on the pattern of microbial colonization and infections. The aim of this preliminary study was to provide current data on the pattern of ICU acquired infections in our hospital.

Patients and Methods: It was a cross sectional study of patients admitted into the ICU who were expected to stay longer than $48 \mathrm{hrs}$ between July 2011 and September 2012. Urine, blood, and tracheal aspirate were collected on days 1, 3 and 5 for microbiological studies. All patients involved in the study had urethral catheter in-situ and received mechanical ventilation in the ICU.

Results: Fifty-nine patients were recruited into the study. The mean age of the patients was $30.08+19.9 \mathrm{yr}$; while the reasons for admissions were respiratory failure $(59.3 \%)$, cardiovascular instability, trauma and neurological diseases. About $30 \%$ of the samples taken from the study sites on arrival in the ICU had positive culture yields. Organisms cultured included Klebsiella oxytoca, Staphylococcus aureus, and Pseudomonas aeruginosa. The urinary tract had the highest number of isolated organisms- 9(60\%), followed by equal number of isolated organisms-3(20\%) in the blood and respiratory tract. Eleven (73.3\%) of the organisms isolated were Gram-negative bacteria, and 4 (26.7\%) were Gram-positive cocci. The commonest bacteria isolates were Staphylococcus aureus (4/26.7\%) and Klebsiella oxytoca (4/26.7\%). A total of 15 ICU- acquired infections were detected in 9 of 59 patients.

Conclusion: The HCIA infection rate was 15\%, and urinary tract infections (UTI) was the commonest hospital acquired infection in our ICU. Klebsiella oxytoca and Staphylococcus aureus were the commonest organisms.
\end{abstract}

Key words: Health care associated infections (HCAI), Hospital acquired infections, Nosocomial infections

\section{Introduction}

Health Care-Associated Infection (HCAI) is a major problem in hospitals across the globe. The incidence is among the highest in patients admitted in the intensive care unit, with increasing mortality and morbidity and huge financial loss (Mahieu et al., 2001; Sheng et al., 2005). Critically ill patients are susceptible to infections due to acquired defects in host defense mechanisms from the immuno-suppressive events of the underlying diseases, recent surgery, trauma and concurrent drug therapy. These patients are also exposed to various invasive devices. Prior colonization has been documented to be an important predisposing factor for nosocomial infection in an intensive care unit (ICU) (Azim et al., 2010). The prevalence of HCAI in hospitalized patients is approximately 6\% (WHO, ICDS/CSR/EPH/2002/12), but was reported as 2.6\% in a recent Nigerian study (Ige et al., 2011 ) and a disproportionate $20 \%$ of these occur in critically ill patients (Jarvis et al., 1991) .

The acuity of illness in intensive care unit patients, invasive diagnoses and the varied therapeutic actions required are partly responsible for higher prevalence. Common sites of HCAI in the ICU include the respiratory tract, urinary tract and blood stream (Inglis TJ, 1989). In order to minimise these infections, it is important to investigate bacteria colonization and HCAI in our ICU. It has been shown that hospitals with effective surveillance program can reduce infection rates of HCAI by one-third (Haley et al., 1985). The study was aimed at finding the incidence of ICU-acquired infection and determining pattern of infection during the first 96 hours after admission to the ICU of University College Hospital (UCH), Ibadan, Nigeria. Also to provide a baseline data for the infection control department and the ICU clinicians.

\section{Patients and Methods}

It was a cross-sectional study conducted in the ICU of an eight hundred (800) bed tertiary care hospital, in South West Nigeria. The hospital receives patients from within the hospital as well referral from outside facilities. The University of Ibadan/ University College Hospital (UCH) joint ethical committee approved the study protocol. An informed consent was obtained from each next of kin of the patients. Patients admitted between July 2011 and September 2012 were prospectively included in the study. Patients who stayed for less than 48 hours were excluded from the study. Social, demographic data and clinical characteristics were obtained from the patients and their next of kin. Modified early warning score was used to assess the severity of illness on admission. 
http://dx.doi.org/10.4314/ajid.v9i2.9

\section{Microbiological studies}

Diagnosis of colonization or infection was based on clinical (presence or absence of fever and leukocytosis) and laboratory evidence. Nosocomial infection was diagnosed according to the standard definitions of CDC (Garner JS, 1988). Appropriate empiric antibiotic was administered as necessary.

\section{Laboratory methods}

The tests were carried in the Bacteriology unit of medical microbiology laboratory, University College Hospital, Ibadan. Sample collection : Tracheal aspirate, blood, wound biopsy and urine were collected from all recruited patients for microscopy, culture and sensitivity tests on days 1,3 , and 5 of ICU admission. Specimens were collected using aseptic technique to prevent contamination. For optimal results, specimens were collected in clean, sterile, wide bore containers.

i. Catheter specimen urine. To collect catheter specimen urine, the urethral catheter was disconnected from the urine bag and then clamped for about 15 mins after which opening of the catheter was cleaned with normal saline, the clamp was removed and urine was allowed to drop into a wide mouth sterile container.

ii. Tracheal aspirate: Tracheal aspirate was collected using a mucus extractor attached to a suction machine; the resulting aspirate was then sealed and transferred to the Laboratory.

iii. Blood: Blood was collected aseptically into a Bactec blood culture bottle. The blood was collected after cleaning the site with povidone-iodine and $70 \%$ alcohol. $5 \mathrm{mls}$ of blood was collected from a peripheral vein, injected into the bactec blood culture bottle and transported to the bacteriology laboratory for incubation in the Bactec 9050 blood culture system. (B.D)

Culture and identification: Samples collected were inoculated on general and selective media like MacConkey agar and blood agar. Inoculated media were incubated aerobically at $35-37^{\circ} \mathrm{C}$ for $18-24 \mathrm{hrs}$.

Characterization: Gram negative bacteria isolated were tested for oxidase, catalase and motility. Isolated organisms that were negative to oxidase were inoculated into peptone broth for about 30 minutes. Thereafter, $1 \mathrm{ml}$ of the broth containing the bacteria was added into the various cups of Microbact Identification kit and then incubated for 18-24 hrs.

\section{Data analysis}

Data was analyzed using the Statistical Package for the Social Sciences (SPSS) Version 17.0 Chicago IL. Frequency tables were used for initial exploration of the data and cross tabulation to study relationships or association between variables. The student t-test and ANOVA was used for analysis of quantitative variables while the Chi- square test was used for all qualitative variables.

\section{Results}

A total of fifty-nine patients were recruited into the study, with a male: female ratio of 1.7:1.0. The mean age was $36.08 \pm 19.9$ (1.5 - 85 years). The indications for admission to the ICU were respiratory failure $(59.3 \%)$, cardiovascular instability $(23.7 \%)$, trauma (11.9\%) and neurologic disease (5.1\%). Thirty-eight (64\%) of those patients admitted into the ICU were transferred from the Accident and Emergency Department, while $18(30 \%)$ of them were admitted from the wards. (Table1) The median Modified Early Warning Score was 6 (2-14).

Table 1: Patient characteristics

\begin{tabular}{|cc|}
\hline \multicolumn{2}{|l|}{ Number (\%) } \\
Gender & \\
Male & $37(62.7)$ \\
Female & $22(37.3)$ \\
Age (Years) & $7(11.9)$ \\
Less than 10 & $5(8.5)$ \\
Above 10-20 & $29(49.1)$ \\
Above 20-40 & $10(16.9)$ \\
Above 40-60 & $8(13.6)$ \\
Above 60 & $35(59.3)$ \\
Co-morbidity diagnosis for ICU admission \\
Respiratory failure & $14(23.7)$ \\
Haemodynamic instability \\
Trauma & $7(11.9)$ \\
Neurologic disease & $3(5.1)$ \\
\multicolumn{2}{|c|}{} \\
Source of admission & $18(30.5)$ \\
Ward & $38(64.4)$ \\
Accident/Emergency & $3(5.1)$ \\
Theatre &
\end{tabular}


Table 2: Growth of bacteria from culture on Day 1.

\begin{tabular}{|l|l|l|l|}
\hline \multirow{2}{*}{ Types of specimen } & \multicolumn{2}{|l|}{ Significant growth of bacteria from Cultures } & \multirow{2}{*}{ Total Samples } \\
\cline { 2 - 3 } & \multicolumn{1}{|c|}{ Positive } & \multicolumn{1}{|c|}{ Negative } \\
\hline Tracheal aspirate & $12(46.2)$ & $14(53.8)$ & 26 \\
\hline Urine & $11(25.0)$ & $33(75.0)$ & 44 \\
\hline Blood & $10(23.8)$ & $32(76.2)$ & 42 \\
\hline Total & $33(29.5)$ & $79(70.5)$ & 112 \\
\hline
\end{tabular}

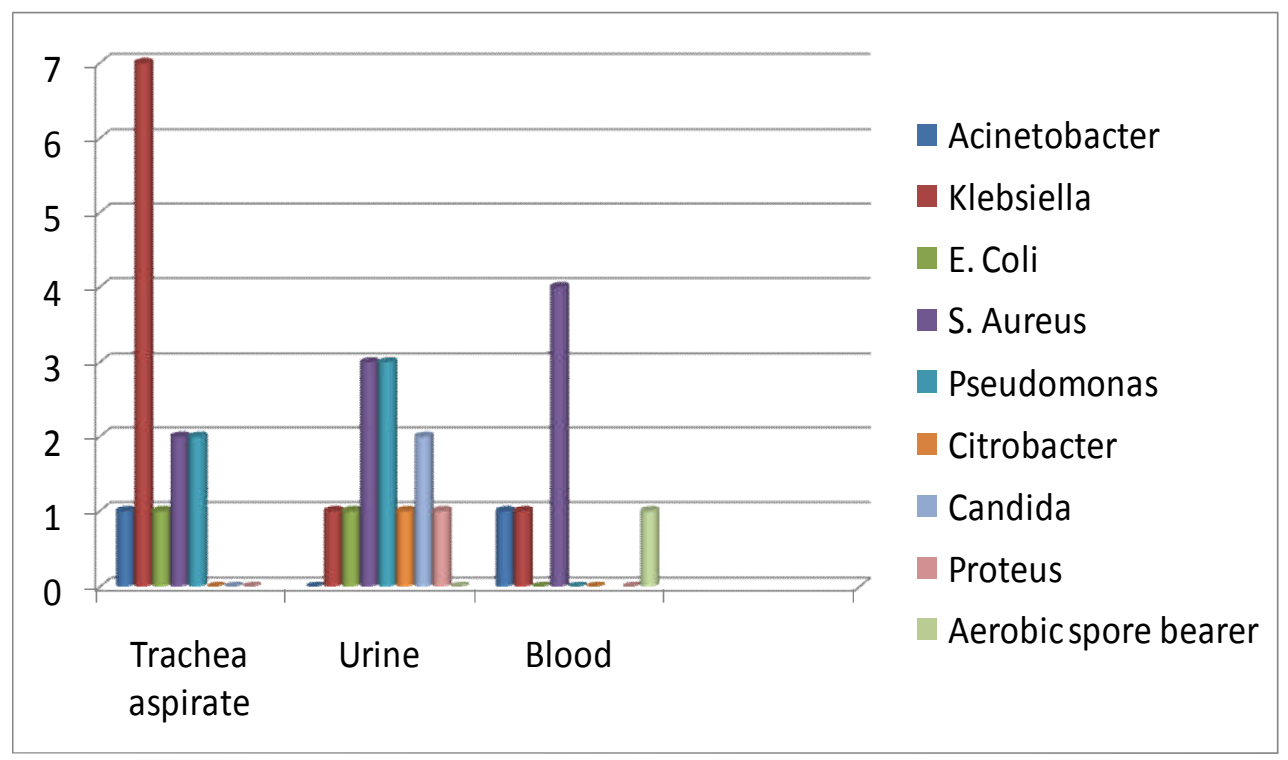

Figure 1: Distribution of bacteria isolates on day 1.

Table 3: Distribution of bacteria isolates according to the source of admission.

\begin{tabular}{|l|c|c|c|}
\hline Bacteria Isolate & $\begin{array}{l}\text { Ward } \\
\mathbf{N = 1 8}\end{array}$ & $\begin{array}{c}\text { Accident/Emergency } \\
\mathbf{N = 3 8}\end{array}$ & $\begin{array}{c}\text { Surgical } \\
\text { Theatre } \\
\mathbf{N = 3}\end{array}$ \\
\hline Acinetobacter baumanii & $4(22.2)$ & 2 & - \\
Klebsiella oxytoca & $1(5.5)$ & 3 & 1 \\
E. Coli & $2(11.1)$ & 2 & - \\
Pseudomonas aeruginosa & $5(27.8)$ & 3 & - \\
S. aureus & - & 8 & - \\
Citrobacter freundi & $1(5.5)$ & - & - \\
Proteus vulgaris & $\mathbf{1 3}(\mathbf{7 2 . 0})$ & $\mathbf{1 9 ( 5 0 . 0 )}$ & $\mathbf{1 ( 3 3 . 0 )}$ \\
\hline Total n(\%) & \multicolumn{2}{|}{} \\
\hline
\end{tabular}

\section{Pattern of Bacterial Colonization}

Samples from some patients were heavily colonised with organisms that were not correlated with healthy oropharyngeal, gastric and urinary tract already on admission to ICU. On the first day of admission, tracheal aspirates, urine and blood yielded twelve (36. 4\%), eleven (33.3\%) and ten $(30.3 \%)$ isolates of different organisms from the laboratory culture results respectively (Table 2). Klebsiella oxytoca was the commonest bacteria 
http://dx.doi.org/10.4314/ajid.v9i2.9

recovered in the tracheal aspirate while Staphylococcus aureus and Pseudomonas aeruginosa were the commonest in the urine. Staphylococcus aureus was the commonest in the blood (Figure1). 30\% of specimens collected from patients on arrival in the ICU yielded isolation of multiple bacteria in 30 $(51 \%)$ out of 59 patients admitted. Staphylococcus aureus $(27.8 \%)$ constitute the majority of isolates recovered from the samples of thirteen patients (72\%) admitted from the wards (Table 3 ).

Table 4: Day 3 outcome of negative cultures of day 1.

\begin{tabular}{|l|c|c|c|}
\hline Specimen & $\mathbf{N}$ & Bacteria isolated & No growth of bacteria after specified period of incubation \\
\hline $\begin{array}{l}\text { Tracheal } \\
\text { aspirate }\end{array}$ & 14 & $\begin{array}{c}2 \\
\text { Acinetobacter baumanii }-1 \\
\text { Citrobacter }-1\end{array}$ & 12 \\
\hline Urine & 33 & $\begin{array}{c}4 \\
\text { E. Coli }-1\end{array}$ \\
$\begin{array}{c}\text { Proteus vulgaris }-1 \\
\text { Klebsiella oxytoca }-1 \\
\text { S. aureus }-1\end{array}$ & 29 \\
\hline Blood & 32 & 0 & 33 \\
\hline
\end{tabular}

Table 5: Day 5 outcome of negative cultures of Day 1.

\begin{tabular}{|c|c|c|c|}
\hline Specimen & $\mathbf{N}$ & Positive culture & $\begin{array}{c}\text { No growth after specified period } \\
\text { of incubation }\end{array}$ \\
\hline $\begin{array}{l}\text { Tracheal } \\
\text { aspirate }\end{array}$ & 14 & $\begin{array}{c}1 \\
\text { Klebsiella oxytoca }\end{array}$ & 13 \\
\hline Urine & 33 & $\begin{array}{c}5 \\
\text { E. coli }-1 \\
\text { Klebsiella } \text { oxytoca }-1 \\
\text { Proteus vulgaris }-1 \\
\text { S. aureus }-1 \\
\text { Serratia }-1\end{array}$ & 28 \\
\hline Blood & 32 & $\begin{array}{c}3 \\
\text { Klebsiella oxytoca }-1 \\
\text { S. aureus }-2\end{array}$ & 30 \\
\hline
\end{tabular}

On the third day of admission, specimens obtained from the sites that had hitherto been negative for bacterial culture on admission yielded significant growth of isolates (Table 4). Acinetobacter baumanii and Citrobacter freundi were isolated from the tracheal aspirate specimens while four urine samples yielded Escherichia Coli, Proteus vulgaris, Klebsiella oxytoca and Staphylococcus aureus.

Laboratory culture results on Day 5 further revealed significant growth of bacteria in those sites where there was no growth on Days 1 and 3. Klebsiella oxytoca was recovered from tracheal aspirate, Klebsiella oxytoca and Staphylococcus aureus were isolated from blood samples while the five urine samples revealed significant growth of Escherichia coli, Klebsiella oxytoca, Proteus vulgaris, Staphylococcus aureus and Serratia spp (Table 5). The distribution of bacteria isolates by site revealed that the urinary tract was colonized with the highest number of isolated organisms$9(60 \%)$, followed by equal number of isolated organisms-3(20\%) in the blood and respiratory tract. Six patients had infections in two of the three sites assessed. A total of $15 \mathrm{ICU}$ - acquired infections were detected in nine of 59 patients, and ICU infection rate was $15 \%$.

Eleven $(73.3 \%)$ of the organisms isolated were Gram-negative bacteria which constituted the highest number while $4(26.7 \%)$ were Grampositive cocci. Among the bacteria isolated, the commonest were Staphylococcus aureus (4/26.7\%) and Klebsiella oxytoca (4/26.7\%).

\section{Discussion}

Bacterial infections and infection control mechanism are of continued and great importance to the general public, health care practitioners, and to those who practice critical care medicine. Colonization with both pathogenic and potentially pathogenic with multiresistant organisms is common among patients in ICU due to high antibiotic pressure in these wards in the hospital.

Our study had shown that organisms were isolated in more than half of the recruited patients from the sampled sites on admission, showing that these ordinarily sterile sites were already colonized before ICU admission. It may not be totally surprising as sepsis is usually one of the main reasons for ICU admission. However, prior bacterial colonization has been found to be a very important risk factor in ICU-acquired infection (Azim et al., 2010). The finding of a high number of bacteria isolates in patients admitted from the hospital wards may not be unexpected with prolong duration of hospital stay that has been associated with higher risk of developing HCAI. However, a randomized controlled trial is needed for a valid conclusion 
on whether patients from the wards will be predisposed more to ICU-acquired infection compared to those from the accident and emergency. Likewise, the development of HCAI is often associated with increased patient morbidity and mortality and therefore prolonged hospital stay (Scheckler, 1980; Plowman et al., 2001). Appropriate infection control is needed to break this vicious cycle responsible for increased morbidity and mortality in susceptible patients.

The prevalence of ICU-acquired infections is often higher in developing rather than in industrialized countries, varying between $4.4 \%$ and $88.9 \%$ (WHO, 2011). Our observation of a NI rate of $15 \%$ is similar to the $14.7 \%$ (Afolabi et al., 2011) obtained in another tertiary hospital in the south-western Nigeria and not far from reported figures in Europe. In a similar study including 1417 centers in 17 European countries, the rate of infection in the ICUs was reported to be $20.6 \%$ (Vincent et al., 1995). Infection rates in ICU reported by other authors are; $21.6 \%$ (Legras et al., 1998), 34\% (Appelgren et al., 2001), 10.6\% (Aly et al., 2008), and 23.9\% (Ylipalosaari et al., 2006).

Commonly reported sites of HCAI infections in ICUs are the respiratory tract, the urinary tract and the bloodstream in descending order respectively (Trilla, 1994; Vincent et al., 1995). The involvement of the sites and causes of infection may also differ between centers. In this study, the urinary tract was the most frequent site of NI and this may not be unconnected to the fact that UTI are the most commonly reported hospital-acquired infection (Ige et al., 2011), as well as urethral catheter being placed for more than seven days in most of our patients. The incidence of HCA UTI was found to be 5\% per catheterized patient per day (Safdar et al., 2001).

Tracheal aspirate yielded highest rate of significant bacterial colonization on the first day of admission into ICU. This is not unexpected as the respiratory failure was the major reason of referral to the ICU often necessitating the use of airway tools and adjuncts before ICU admission.

Nosocomial respiratory tract infection rate was expected to be higher with respiratory failure as a major reason for ICU admission with subsequent mechanical ventilation. However, our small cohort size may be partly responsible for the result we obtained. Also, the infrequent use of invasive haemodynamic monitoring devices may be responsible for the low nosocomial blood stream infection observed in this study.

This study showed that Gram-negative bacteria were the commonest group of organisms that colonized the ordinarily sterile sites of recruited patients on admission. It is in conformity with what had been widely reported in other studies. (Vincent et al., 1995; Richards et al., 2000). In our study, Klebsiella oxytoca and Staphylococcus aureus were responsible for most infections, followed by Escherichia coli and Proteus vulgaris, Acinetobacter baumanii, Serratia species and Citrobacter freundi. Esen et al. (2004) reported Pseudomonas aeruginosa (20.8\%), Acinetobacters (18.2\%), Staphylococcus aureus (18.2\%) and Klebsiella species (16.1\%) as the commonest organisms (Esen \& Leblebicioglu, 2004). Staphylococcus aureus (30.9\%), Acinetobacter species (26.8\%), Pseudomonas aeruginosa $(12.4 \%)$ were the most frequent etiologic agents reported in another study (Meric et al., 2005).

Acinetobacter baumanii and Citrobacter freundi were the commonest agents found to be colonising the patients with respiratory failure. Acinetobacter often colonizes the respiratory tract and wound, and they are special threats in burns unit. Outbreaks can be difficult to control, and there are case reports where entire ICU has been forced to close down due to such outbreaks (Vincent et al., 1995).

Staphylococcus aureus was also found to be the commonest organisms colonising the patients transferred from the wards and Accidents \& Emergency units in this study. This bacteria has maintained its position as the leading pathogenic organisms in the ICU and caused $30 \%$ of the ICU-acquired infections in a study conducted in 1995.(Vincent et al., 1995) It is also one of the commonest in the late-onset Ventilator acquired Pneumonia (VAP) (Vincent et al., 2006).

Some of the bacteria isolates in our study are of immense clinical importance. This is because they are often associated with infections like bronchopneumonia, wound sepsis, bacteremia, meningitis and urinary tract infections with active resistance to common antibiotics.

Limitations of our study include the small sample size and non-inclusion of risk factors for the development of ICU-acquired infection. This study is a pilot study of a much bigger research work. In the main study, risk factors, characterization of the antibiotic profile as well as the antibiotic-resistant pattern of the isolated bacteria will be assessed.

\section{Conclusion}

The NI infection rate was $15 \%$. This study had shown that urinary tract infection is the most common nosocomial infection in our ICU and that Klebsiella oxytoca and Staphylococcus aureus are the most common microbes in the development of nosocomial infections in our ICU. The p resent study has emphasised that there is a need to implement and continuously monitor infection control programmes in our ICU.

\section{Acknowledgement}

We will like to acknowledge the support of the resident doctors, Nurses, relative of the study participants.

\section{References}

1. Afolabi O T, Onipede A O, Omotayo S K, Oluyede C O, Olajide F O, Oyelese A O and Olawande O. 2011. Hospital Acquired Infection in Obafemi Awolowo University Teaching Hospital, Ile-Ife, Southwest, Nigeria: A Ten Year Review (2000-2009) Sierra Leone Journal of Biomedical Research, 3:110-115.

2. Aly N Y, Al-Mousa H H and Al Asar el S M. 2008. Nosocomial infections in a medical-surgical intensive care unit. Med Princ Pract, 17:373-377.

3. Appelgren P, Hellstrom I, Weitzberg E, Soderlund V, Bindslev L and Ransjo U. 2001. Risk factors for nosocomial intensive care infection: a long-term prospective analysis. Acta Anaesthesiol Scand, 45:710-719.

4. Azim A, Dwivedi M, Rao P B, Baronia A K, Singh R K, Prasad K N, Poddar B, Mishra A, Gurjar M and Dhole T N. 2010. Epidemiology of bacterial colonization at intensive care unit admission with emphasis on extended-spectrum beta-lactamase- and metallo-beta-lactamase-producing Gram-negative bacteria--an Indian experience. J Med Microbiol, 59:955-960.

5. Esen S and Leblebicioglu H. 2004. Prevalence of nosocomial infections at intensive care units in Turkey: a multicentre 1-day point prevalence study. Scand J Infect Dis, 36:144-148.

6. Garner JS J W, Emori TG, Horan TC, Hughes JM. 1988. CDC definitions for nosocomial infections. Am J Infect Control, 16:128-140. 
http://dx.doi.org/10.4314/ajid.v9i2.9

7. Haley R W, Culver D H, White J W, Morgan W M, Emori T G, Munn V P and Hooton T M. 1985. The efficacy of infection surveillance and control programs in preventing nosocomial infections in US hospitals. Am J Epidemiol, 121:182-205.

8. Ige O K, Adesanmi A A and Asuzu M C. 2011. Hospital-acquired infections in a Nigerian tertiary health facility: An audit of surveillance reports. Niger Med J, 52:239-243.

9. Inglis TJ M M, Jones G, et al. 1989. Tracheal tube biofilm as a source of bacterial colonization of the lung. J Clin Microbiol., 27:2014-2018.

10. Jarvis W R, Edwards J R, Culver D H, Hughes J M, Horan T, Emori T G, Banerjee S, Tolson J, Henderson T, Gaynes R P and et al. 1991. Nosocomial infection rates in adult and pediatric intensive care units in the United States. National Nosocomial Infections Surveillance System. Am J Med, 91:185S-191S.

11. Legras A, Malvy D, Quinioux A I, Villers D, Bouachour G, Robert R and Thomas R. 1998. Nosocomial infections: prospective survey of incidence in five French intensive care units. Intensive Care Med, 24:1040-1046.

12. Mahieu L M, Buitenweg N, Beutels P and De Dooy J J. 2001. Additional hospital stay and charges due to hospital-acquired infections in a neonatal intensive care unit. J Hosp Infect, 47:223-229.

13. Meric M, Willke A, Caglayan C and Toker K. 2005. Intensive care unit-acquired infections: incidence, risk factors and associated mortality in a Turkish university hospital. Jpn J Infect Dis, 58:297-302.

14. Plowman R, Graves N, Griffin M A, Roberts J A, Swan A V, Cookson B and Taylor L. 2001. The rate and cost of hospital-acquired infections occurring in patients admitted to selected specialties of a district general hospital in England and the national burden imposed. $\mathrm{J}$ Hosp Infect, 47:198-209.

15. Richards M J, Edwards J R, Culver D H and Gaynes R P. 2000. Nosocomial infections in combined medical-surgical intensive care units in the United States. Infect Control Hosp Epidemiol, 21:510-515.

16. Safdar N, Crnich C J and Maki D G. 2001. Nosocomial Infections in the Intensive Care Unit Associated with Invasive Medical Devices. Curr Infect Dis Rep, 3:487-495.

17. Scheckler W E. 1980. Hospital costs of nosocomial infections: a prospective three-month study in a community hospital. Infect Control, $1: 150-152$.

18. Sheng W H, Wang J T, Lu D C, Chie W C, Chen Y C and Chang S C. 2005. Comparative impact of hospital-acquired infections on medical costs, length of hospital stay and outcome between community hospitals and medical centers. J Hosp Infect, 59:205-214.

19. Trilla A. 1994. Epidemiology of nosocomial infections in adult intensive care units. Intensive Care Med, 20 Suppl 3: S1-4.

20. Vincent J L, Bihari D J, Suter P M, Bruining H A, White J, Nicolas-Chanoin M H, Wolff M, Spencer R C and Hemmer M. 1995. The prevalence of nosocomial infection in intensive care units in Europe. Results of the European Prevalence of Infection in Intensive Care (EPIC) Study. EPIC International Advisory Committee. JAMA, 274:639-644.

21. Vincent J L, Sakr Y, Sprung C L, Ranieri V M, Reinhart K, Gerlach H, Moreno R, Carlet J, Le Gall J R and Payen D. 2006. Sepsis in European intensive care units: results of the SOAP study. Crit Care Med, 34:344-353.

22. WHO. 2011. Health care associated infections fact sheet. World Health Organization.

23. WHO. ICDS/CSR/EPH/2002/12. Prevention of hospital-acquired infections. A practical guide

24. Ylipalosaari P, Ala-Kokko T I, Laurila J, Ohtonen P and Syrjala H. 2006. Intensive care acquired infection is an independent risk factor for hospital mortality: a prospective cohort study. Crit Care, 10:R66. 